www.jmscr.igmpublication.org

Impact Factor 5.84

Index Copernicus Value: 83.27

ISSN (e)-2347-176x ISSN (p) 2455-0450

crossref DOI: _https://dx.doi.org/10.18535/jmscr/v5i8.82

Journal Of Medical Science And Clinical Research

\title{
Prevalence of Generalized Anxiety Disorder among the Patients Attending a Peripheral Health Center in Kashmir Valley
}

\author{
Authors \\ Kousar Sideeq ${ }^{1}$, Taha Ayub ${ }^{1}$, Umar Nazir ${ }^{1}$ \\ Senior Resident, Department of Community Medicine, Government Medical College, Srinagar
}

\begin{abstract}
Background: Anxiety disorder is one of the common mental disorders emerging in the current world. Among all type of anxiety disorder the prevalence of generalized anxiety disorder is around 1-5\% among Indian population. In the valley of Kashmir very little data is available in literature regarding this issue. Our study aimed to contribute on the baseline data regarding generalized anxiety disorder in Kashmir.

Objective: To find out the prevalence of generalized anxiety disorder among the patients attending general $O P D$ in a peripheral health center of district Srinagar block hazaratbal.

Methods: The study was conducted under the department of Community Medicine GMC Srinagar. All patients attending general OPD were included in the study with the exclusion of the patients who were critically ill and needed immediate referral; patients with acute severe trauma, patients with age less than 18 years were also excluded from the study. The study was conducted for 2 months. After selection of each patient, presence of generalized anxiety disorder was assessed by using the DSM V criteria, GAD 7 scale was used to assess the severity of disorder.

Results: A total of 1553 patients were assessed for generalized anxiety disorder. Among them, 15 patients were found having generalized anxiety disorder according to DSM 5 giving the prevalence of around 0.96\%.Among these, $86 \%$ were females. About two third patients belonged to class II socioeconomic status according to modified Kuppasuami scale.

Conclusion: Prevalence of GAD in this urban population is approximately close to the prevalence at the national level. This study points to the need for proper assessment of patients at each peripheral health center to diagnose such patients at earlier severity of the disorder so to prevent social economical and physical deterioration of such patients.

Key Words: Anxiety, Mental Disorders, Prevalence, Kashmir.
\end{abstract}

\section{Introduction}

Anxiety disorder is one of the common mental disorders emerging in the current world. Occasional anxiety is a normal part of life. One might feel anxious when faced with a problem at work, before taking a test. But anxiety disorders involve more than temporary worry or fear and can interfere with daily activities such as job performance, school work, and relationships. ${ }^{1}$ There are several different types of anxiety disorders like generalized anxiety disorder, panic disorder, and social anxiety disorder. Generalized anxiety disorder (GAD) is characterized by excessive worry about a variety of everyday problems for at least 6 months. $^{2}$ Generalized anxiety disorder (GAD), also known as "chronic 
anxiety neurosis," is characterized by chronic "free-floating anxiety," accompanied by such autonomic symptoms as tremor, tachycardia, and diaphoresis. ${ }^{3}$ Among all type of anxiety disorder the prevalence of generalized anxiety disorder is around 1-5\% among Indian population. They are the sixth leading cause of disability worldwide with $4 \%$ of all YLD (years lived with disability). It is seen more commonly in females as compared to males. Roughly 273 million had an anxiety disorder as of $2010 .{ }^{4}$ In the valley of Kashmir, very little data is available in literature regarding this issue. Our study aimed to contribute to the baseline data regarding generalized anxiety disorder in Kashmir. The study was conducted with the intention of finding out the prevalence of generalized anxiety disorder among the patients attending general OPD in a peripheral health center of district Srinagar Block Hazaratbal.

\section{Material \& Methods}

The study was conducted in urban field practice area of department of Community Medicine GMC Srinagar. All patients attending general OPD who consented to participate in the study were included. The patients who were critically ill and needed immediate referral; patients with acute severe trauma, patients with age less than 18 years were excluded from the study. The study was conducted for 2 months. After selection of each patient, the respondent was interviewed for the presence of generalized anxiety disorder using DSM V criteria. GAD 7 scale was used to assess the severity of disorder. A 7-item scale-the GAD-7 is a useful tool with strong criterion validity for identifying probable cases of GAD and the scale is also an excellent severity measure. ${ }^{5}$ Any patient who was not willing to participate was excluded from the study.

\section{Results}

A total of 1553 patients were interviewed.
Table no. 1: Socio-demographic characteristics of the patients interviewed $(n=1553)$ :

\begin{tabular}{|l|c|c|}
\hline $\begin{array}{l}\text { Socio-demographic } \\
\text { characteristics }\end{array}$ & $\begin{array}{c}\text { Numbers } \\
(\mathrm{n})\end{array}$ & $\begin{array}{c}\text { Percentage } \\
(\%)\end{array}$ \\
\hline 1.Sex & 675 & 43.4 \\
Male & 878 & 56.6 \\
Female & 170 & 10.9 \\
\hline 2. Age & 297 & 19.1 \\
$<20$ & 417 & 26.8 \\
$21-30$ & 375 & 24.1 \\
$31-40$ & 294 & 19.1 \\
$41-50$ & & \\
$>50$ & 834 & 53.7 \\
\hline 3. Educational Qualification & 322 & 20.7 \\
Illiterate & 264 & 16.9 \\
Upto Matric(10 $\left.{ }^{\text {th }}\right)$ & 133 & 8.7 \\
Higher secondary (12 $\left.{ }^{\text {th }}\right)$ & & \\
Graduate \& above & 866 & 55.7 \\
\hline 4. Occupation & 311 & 20.2 \\
Home maker & 112 & 7.2 \\
Laborer & 264 & 16.9 \\
Govt Employ & & \\
Others & 567 & 36.5 \\
\hline 5.Socio-Economic Class & 411 & 26.4 \\
Class 1 & 575 & 37.1 \\
\hline Class 2 & & \\
Class 3 \& above & & \\
\hline
\end{tabular}

$56 \%$ of respondents were female and $70 \%$ were belonging to economically reproductive age group. Among the respondents, $53.7 \%$ were illiterate and $55 \%$ were home maker by occupation.

Table no. 2: Distribution of the sample according to the presence of GAD:

\begin{tabular}{|l|c|c|}
\hline GAD & No. of frequencies & Percentage (\%) \\
\hline Present & 15 & 0.96 \\
\hline Absent & 1538 & 99.03 \\
\hline
\end{tabular}

Table no. 3: Distribution of the patients with GAD according to different variables:

\begin{tabular}{|l|c|c|c|}
\hline Variables & \multicolumn{2}{|c|}{ Female } \\
\hline Gender Distribution & Male & \multicolumn{2}{|c|}{ Fem (86.7) } \\
& $2(13.3)$ & \multicolumn{2}{|c|}{ Literate } \\
\hline Education & Illiterate & \multicolumn{2}{|c|}{$4(26.7)$} \\
\hline Socio- Economic class & $11(73.3)$ & Class 2 & Class 3 \& \\
& Class 1 & $11(73.3)$ & above \\
& $0(0)$ & & $4(26.7)$ \\
\hline
\end{tabular}

Table no.4: Distribution of patients with GAD according to the severity:

\begin{tabular}{|l|c|c|}
\hline Severity & Male $\mathrm{n}(\%)$ & Female n(\%) \\
\hline Mild & $1(6.6)$ & $6(40)$ \\
\hline Moderate & $0(0)$ & $5(33.3)$ \\
\hline Severe & $1(6.6)$ & $2(13.5)$ \\
\hline
\end{tabular}

Table no 2 reveals that only 15 patients were having GAD, among whom $86 \%$ were females and $74 \%$ were belonging to socio economic class 
2. Regarding the severity, $40 \%$ were suffering from mild form whereas only one patient had severe form of GAD.

\section{Discussion}

The present study revealed $0.96 \%$ prevalence of GAD among the patients attending the peripheral Health centers of Block Hazratbal. There is a limitation of this study that the study population does not represent the population truly but this study gives a baseline data about the GAD in our settings.

A very low prevalence of $<1 \%$ was reported by this study which is very less as compared to other studies. Olfson et al has reported the prevalence of GAD as $0.4 \%$ in their study. ${ }^{6,15}$ However there are other studies which has reported higher prevalence of GAD. ${ }^{7,8,9,10,11,12,13,14,16,17}$ The study reported higher prevalence of GAD among females, illiterates and those belonging to lower socio economic class. ${ }^{6,7,9,11,12,14,15}$

\section{References}

1. Transforming the understanding and treatment of mental illnesses. Anxiety Disorders. Available at https://www.nimh.nih.gov/health/topics/an xiety-disorders/index.shtml. Last accessed on 25-07-2017.

2. Transforming the understanding and treatment of mental illnesses.Generalized Anxiety Disorder Among Adults . Available at https://www.nimh.nih.gov/health/statistics/ prevalence/generalized-anxiety-disorderamong-adults.shtml. Last accessed on 2307-2017.

3. Generalized Anxiety Disorder (DSM-IVTR \#300.02). Available at http://www.brown.edu/Courses/BI_278/Ot her/Clerkship/Didactics/Readings/gad.pdf. Last accessed on 23-07-2017.

4. Anxiety Disorders And The Homeopathy Management. Introduction. Available at https://www.nhp.gov.in/Anxiety-
Disorders_mtl. Last accessed on 25-072017. Last accessed on 25-07-2017.

5. Robert L. Spitzer, Kurt Kroenke, Janet B. W. Williams,Bernd Lowe. A Brief Measure for Assessing Generalized Anxiety Disorder. The GAD-7. Arch Intern Med.2006; 166:1092-1097

6. Mark Olfson, Bruce Fireman, Myrna M. Weissman, Andrew C. Leon, David V. Sheehan, Roger G. Kathol, Christina Hoven, Dr.P.H., and Leslie Farber. Mental Disorders and Disability among patients in a Primary Care Group Practice. Am J Psychiatry 1997; 154:1734-1740.

7. Raakhee.A, Aparna. A Study On The Prevalance Of Anxiety Disorders Among Higher Secondary Students. GESJ: Education Science and Psychology 2011;1(18).

8. Vishal Chhabra, MS Bhatia, Sahil Gupta, Pankaj Kumar, Shruti Srivastava. Prevalence of Social Phobia in schoolgoing adolescents in an urban area. Delhi Psychiatry Journal 2009; 12:(1).

9. Marc Ansseau, Benjamin Fischler, Michel Dierick, Adelin Albert, Sophie Leyman, Annick Magnon. Socio Economic Correlates of Generalized Anxiety Disorders and major depression in Primary care:The Gadis II study(Generaliaed anxiety and Depression Impact survey II).Depression and anxiety 2007: 0;1-8.

10. Leon AC, Olfson M, Broadhead WE, Barrett JE, Blacklow RS, Keller MB, Higgins ES, Weissman MM. Prevalence of mental disorders in primary care. Implications for screening. Arch Fam Med. 1995 Oct;4(10):857-61.

11. Carter RM, Wittchen HU, Pfister H, Kessler RC. One-year prevalence of subthreshold and threshold DSM-IV generalized anxiety disorder in a nationally representative sample. Depress Anxiety. 2001;13(2):78-88. 
12. J. K. Trivedi and Pawan Kumar Gupta. An overview of Indian research in anxiety disorders.. Indian J Psychiatry. 2010 Jan; 52(11): 210-18.

13. Sahoo S, Khess CRJ. Prevalence of depression, anxiety, and stress among young male adults in India: a dimensional and categorical diagnoses-based study. Nerv Ment Dis. 2010 Dec;198(12):901-4.

14. Nilsson J, Ostling S, Waern M, Karlsson B, Sigstrom R, Guo X, Skoog I. The 1month prevalence of generalized anxiety disorder according to DSM-IV, DSM-V, and ICD-10 among nondemented 75-yearolds in Gothenburg, Sweden. Am J Geriatr Psychiatry. 2012 Nov;20(11):963-72.

15. Christopher Gale, Oliver Davidson. Generalised anxiety disorder. BMJ. 2007 Mar 17; 334(7593): 579-581.

16. Analucia A. Alegria,Deborah S. Hasin, Edward V. Nunes, Shang-Min Liu, Carrie Davies, Bridget F. Grant, and Carlos Blanco. Comorbidity of Generalized Anxiety Disorder and Substance Use Disorders: Results from the National Epidemiologic Survey on Alcohol and Related Conditions.J Clin Psychiatry. 2010 Sep; 71(9): 1187-1195.

17. Adomas Bunevicius, Margarita Staniute, Julija Brozaitiene, Victor JM Pop, Julius Neverauskas, Robertas Bunevicius . Screening for anxiety disorders in patients with coronary artery disease. Health and Quality of Life Outcomes2013; 11:37. 